Año 16, Vol. 11, número 21, agosto-diciembre 2021

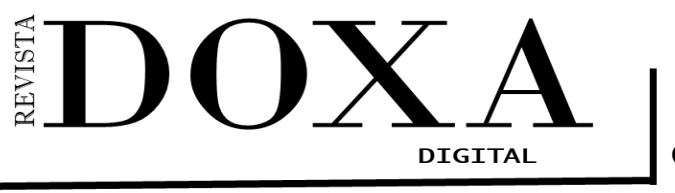

eISSN: 2594-2786

Ponencia presentada en la mesa 5

Ponencia presentada el 1 de junio del 2021

DOI: $10.52191 /$ rdojs.2021.235

Pág.: 212-225

"Estudios de pregrado en comunicación, organizaciones y gestión"

Primer Coloquio de Estudiantes y Egresados de Licenciatura y Posgrado

Ciudad Juárez, México 1 y 2 de junio 2021

\title{
Perspectiva de la sociedad en la adopción de menores de edad en el desarrollo psicosocial entre familias homoparentales en Ciudad Juárez, Chihuahua
}

\section{Society's perspective on the adoption of minors in psychosocial development}

María Isabel Arjón Galicia *

\section{RESUMEN}

El presente trabajo de investigación analizara el tema en relación a la adopción de los menores de edad por parejas homosexuales, con la finalidad de conocer el impacto que tiene en los menores de edad al momento de desarrollarse y crecer dentro de una familia homoparental, y de esta manera determinar si la adopción de menores de edad entre familias homoparentales afecta en su desarrollo psicosocial.

PALABRAS CLAVE: Familia, Familia Homoparental, Adopción, Desarrollo Psicosocial, Interés Superior del menor.

\section{ABSTRACT}

This research work will analyze the issue in relation to the adoption of minors by homosexual couples, in order to know the impact it has on minors at the time of developing and growing up within a homoparental family, and of In this way, determine if the adoption of minors between homoparental families affects their psychosocial development.

KEYWORDS. Family, Homoparental Family, Adoption, Psychosocial Development, Higher Interest of the minor.

* Licenciada en Derecho egresada de la Universidad Autónoma de Ciudad Juárez, Alumna de la Maestría en Derechos Humanos con Perspectiva de Género del Instituto Estatal de Seguridad Pública. Servidora Pública adscrita a la Fiscalía General del Estado de Chihuahua. Contacto: issaarjon@gmail.com 
Año 16, Vol. 11, número 21, agosto-diciembre

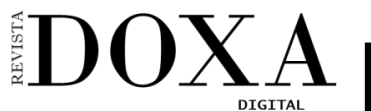

pISSN: 2395-8758 eISSN: 2594-2786
Sección: Dossier

DOI: $10.52191 /$ rdojs.2021.235

Pág.:212-225
María Isabel Arjón Galicia

Perspectiva de la sociedad en la adopción..

\section{Introducción}

El tema en relación a la adopción de los menores de edad por parejas homosexuales es un tanto controversial, despertando el interés por conocer el impacto que puede generar en menores de edad al momento de desarrollarse y crecer dentro de una familia homoparental. A partir del reconocimiento del matrimonio entre personas del mismo sexo, surge la necesidad de que se les reconozcan los mismos derechos que a un matrimonio heterosexual, destacando la adopción. Muchas personas dentro de la sociedad están de acuerdo con la legalización del matrimonio igualitario respetando de esta manera la libertad de elección de cada persona respecto a su orientación sexual, sin embargo no están de acuerdo en que estas puedan formar familia por medio de la adopción, argumentando que podrían poner en riesgo el desarrollo psicosocial de los menores de edad, mientras que otros lo ven como inmoral en base a que se menciona que a través de ella se quebranta la definición tradicional de familia.

Familia

Desde que se tiene uso de razón han existido las familias, esto dándose mediante la perspectiva de la unión, donde dos personas con sentimientos y fines en común deciden tener una convivencia bajo un mismo techo, posteriormente vienen los hijos, la educación en las funciones sexuales y sociales de éstos, y tomar la decisión de soltarlos para la formación de nuevas familias, de esta manera quedando sola la pareja; según un ciclo de vida.

Y es así como lo menciona la autora Isabel Cristina Flores Osorio en el siguiente párrafo:

La familia es un núcleo social primordial, el más natural y antiguo de todos, es una verdadera célula de la sociedad, base y piedra angular del ordenamiento social, no sólo tiene la misión de asegurar la reproducción e integración de la humanidad por generaciones, sino también la de formar y desarrollar los más elevados sentimientos, tales como el de solidaridad, superación, altruismo, los cuales son necesarios para el mantenimiento saludable y próspero de la sociedad (Flores Osorio, La Adopción por las Familias Homoparentales en México, 2017, pág. 374)

El concepto de familia cambió significativamente, fue adquiriendo nuevos matices al incorporarse nuevos personajes, al hacerse notar aquellos que se encontraban invisibilizados o excluidos; entre ellos abuelos, tíos, primos entre otros, que llegaron para conformar lo conocido hoy en día como familia política, o también llamada familia extensa. También existen otras situaciones tales como los divorcios de la misma manera dieron paso a nuevas formas de familia. Lo único cierto es que la dinámica social sigue avanzando inclusive hasta llegar a conformarse una pareja con dos personas del mismo sexo con uno o más hijos en común, es decir, familia homoparental.

En el artículo 5 de la Convención sobre los Derechos del Niño, se ve desarrollado en las Observaciones Generales del Comité de los Derechos del Niño donde refiere:

"El término "familia" debe interpretarse en un sentido amplio que incluya a los padres biológicos, adoptivos o de acogida o, en su caso, a los miembros de la familia ampliada o a la comunidad según establezca la costumbre" (Flores Osorio, La Adopción por las Familias Homoparentales en 
Año 16, Vol. 11, número 21, agosto-diciembre

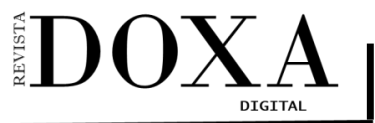

pISSN: 2395-8758 elSSN: 2594-2786
Sección: Dossier

DOI: $10.52191 /$ rdojs.2021.235

Pág.:212-225
María Isabel Arjón Galicia

Perspectiva de la sociedad en la adopción..

México, 2017, pág. 375)

La familia constituye uno de esos grupos humanos que inmersa dentro del macro grupo que constituye la sociedad, se integra y desarrolla teniendo en cuenta la situación económica- política y social imperante. (Martínez Vasallo, 2015, pág. 524)

Una familia puede estar constituida por vínculos consanguíneos o por vínculos compuestos reconocidos legalmente y socialmente como lo es la adopción. El concepto de familia ha sufrido transformaciones lo largo de la historia, conforme a los avances que han existido dentro de la sociedad según sus costumbres, culturas, religiones y legislación de cada país.

El derecho a una familia es uno de los derechos fundamentales más importantes de los derechos humanos, es donde el ser humano comienza a aprender y comienza a desarrollarse y prepararse para convivir en armonía con la sociedad.

La autora María Elena Benítez Pérez nos ofrece como definición de familia para comprender un poco más respecto a esto como:

La familia está formada por dos o más personas unidas por el afecto, el matrimonio o la filiación, que viven juntas, ponen sus recursos económicos en común y consumen conjuntamente una serie de bienes en su vida cotidiana (Benítez Pérez, 2017, pág. 61)

\section{Matrimonios Homosexuales en México}

Uno de los principales derechos reconocidos a las personas homosexuales es el matrimonio; esta es una institución creada por la sociedad donde ha tenido diversas modalidades y formas, las cuales han tenido que ver con la forma de entender las relaciones existentes entre personas del mismos sexo; efectivamente, desde tiempos muy remotos dentro de la historia la homosexualidad ha pasado por todas las etapas de la humanidad, no es algo nuevo; según Salinas Hernández viene "desde Mesopotamia, Canaán, Egipto, la Grecia clásica y el mundo helénico, pasando por los romanos y su imperio, la Edad Media y el Renacimiento, hasta llegar a nuestros días" (Salinas Hernández, 2017, pág. 95)

A partir del reconocimiento del matrimonio entre personas del mismo sexo o matrimonio igualitario surge la necesidad de que se les otorguen los mismos derechos que a un matrimonio heterosexual, de ahí destaca la adopción, tema que nos compete para la investigación que se lleva a cabo.

El derecho ha ido evolucionado de acuerdo con las exigencias sociales, ya que no puede mantenerse un estilo único en las leyes esto debido a que la sociedad en la que nos desenvolvemos se encuentra en un constante cambio, es por esto que el legislador debe adaptarse a todos esos cambios para de esta manera dar la protección que la Constitución otorga a todos los individuos por el hecho de ser mexicanos, de ahí, es que las personas LGBTIQ+ y sobre todo las personas homosexuales han hecho lo posible para que el Estado reconozca sus derechos, ya que estos les han sido negados durante mucho tiempo por causa de su orientación sexual, a la fecha han ob- 
Año 16, Vol. 11, número 21, agosto-diciembre

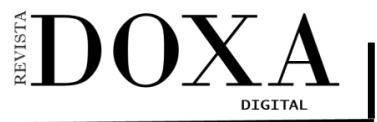

Sección: Dossier

DOI: 10.52191/rdojs.2021.235

Pág.:212-225
María Isabel Arjón Galicia

Perspectiva de la sociedad en la adopción..

teniendo sentencias favorables de la Suprema Corte de Justicia de la Nación, así como la protección de la Constitución Política de los Estados Unidos Mexicanos, lo que ha provocado en la obtención del matrimonio, y solo en unos Estados de la República Mexicana, existe en otros que se les prohíbe el adoptar, por causa de los prejuicios que existen en torno a las personas homosexuales, lo cual les ha dado la oportunidad de contraer matrimonio pero no la de formar una familia; el legislador ha argumentado que se verá afectado el interés superior del menor, además de los prejuicios de la sociedad donde expresan que no debería existir este tipo de familias, pues consideran que los menores tendrán malos padres e incluso que pueda llegar a darse un abuso en perjuicio de los menores, así pues, se lastimarían los derechos de los de las personas homosexuales además de los menores, esto por causa de prejuicios sociales que impiden la labor del legislativo en favor de la comunidad LGBTIQ+.

A raíz de todo lo acontecido durante los últimos años en su artículo "El derecho a la adopción por parejas homosexuales" Reyes Domínguez nos menciona que:

La adopción por parte de matrimonios entre personas del mismo sexo es una realidad en la Ciudad de México desde abril del año 2010, luego en Coahuila a partir del 2014 y en Campeche en octubre del 2016, donde el Alto Tribunal falló a favor de la adopción de niños por parejas homosexuales al declarar inconstitucional la Ley de Sociedades Civiles de Convivencia. En el primer caso, la posibilidad se dio luego de aprobados los cambios en el Código Civil en diciembre del 2009; la posibilidad de que parejas del mismo sexo puedan adoptar en México ha generado diversos puntos de vista de acuerdo a la moral y costumbres que les han sido inculcadas a lo largo su vida (Arenas Valdés \& Reyes Martínez , 2019, pág. 2)

\section{Familia Homoparental}

En pleno siglo XXI, la familia se ha diversificado estructuralmente, una de las variantes de familia nuclear, son las homoparentales, las cuales están conformadas por padres con orientación sexual homosexual; y no se habla de un fenómeno nuevo, puesto que ha existido desde tiempos muy remotos, es donde actualmente se vive una intensa aceleración a raíz de que se dio el reconocimiento legal del matrimonio entre personas del mismo sexo en muchas naciones.

El abordar el tema de la homoparentalidad o la familia homoparental deja ver que es un concepto único. Es un término que hasta hace algunos años no era tan familiar como hoy en día, a raíz del surgimiento de reformas aprobadas en las que permites y respetan los derechos a los que son acreedores las parejas homosexuales.

El término denominado familia homoparental no es muy sonado dentro de la sociedad aun, ya que se encuentra en desarrollo a partir de que a las parejas homosexuales se les permito el matrimonio, y posterior a esto se da la necesidad de tener los mismos derechos que una pareja heterosexual, y bien mencionado en el artículo la familia homoparental en la realidad y la diversidad familiar actual en donde los autores refieren:

Indiscutiblemente, la dinámica social actual, que ha ampliado el ciclo familiar basado en diferentes etnias, mezcla de culturas, familias monoparentales, divorcios y nuevas nupcias, propicia y 
Año 16, Vol. 11, número 21, agosto-diciembre Sección: Dossier

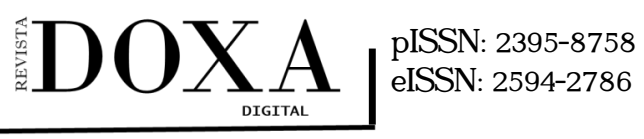

Pág.:212-225
María Isabel Arjón Galicia

DOI: $10.52191 /$ rdojs.2021.235

Perspectiva de la sociedad en la adopción.

da la posibilidad de la apertura hacia la vida familiar del hombre o de la mujer homosexual. Así, se constituyen las denominadas familias homoparentales, donde las parejas de hombres o de mujeres, deciden conformar un hogar con hijos de uniones heterosexuales anteriores, o bien recurren a la adopción, acogimiento de menores, reproducción asistida o la maternidad subrogada. (Placeres Hernández, Olver Moncayo, Rosero Mora, Urgilés Calero, \& Abdala-Jalil Barbadillo, La familia homoparental en la realidad y la diversidad familiar actual, 2017, pág. 363)

Actualmente, respecto al tema en materia de parentalidad de las personas de la diversidad sexual los estudios aún no han atendido un conjunto teórico articulado, estos se han ido desarrollando conforme el avance dentro del colectivo LGBTIQ+, pues ha conseguido reconocimiento tanto en cuestiones legales como sociales; y ha necesitado del apoyo legal, político, académico, social y médico para respaldar sus demandas. Además, ha despertado el interés por conocer el impacto en menores de edad al momento de desarrollarse y crecer dentro de una familia homoparental.

Y es por eso que se realizan cuestionamientos los cuales se describen en el siguiente párrafo:

Las familias homoparentales están capacitadas para educar y criar satisfactoriamente a sus hijos e hijas. La orientación sexual de los progenitores, no es un indicador que sirva para evaluar la función educadora de los padres y madres. Padres e hijos de las familias homoparentales, deben apropiarse de elementos resilientes, que les permitan crecerse, ante cualquier manifestación social, potencialmente negativa hacia ellos (Placeres Hernández, Olver Moncayo, Rosero Mora, Urgilés Calero, \& Abdala-Jalil Barbadillo, La Familia Homoparental en la Realidad y la Diversidad Familiar Actual, 2017)

Se deriva de este interés un concepto de familia homoparental donde Castaño, Sánchez y Viveros refieren que:

La familia homoparental alude a familias constituidas por personas del mismo sexo, bien sean gay o lesbianas que optan por asumir un rol de paternidad o maternidad, según sea el caso. Así, entre los conceptos encontrados, producto de la revisión bibliográfica, resultan ser pocos los autores que presentan posturas diferentes con respecto al mismo (Castaño Suárez, Sánchez Trujillo, \& Viveros Chavarría, 2018, pág. 63)

Así mismo nos mencionan en este mismo artículo que existe el mismo interés por otros autores que han hecho aportes:

De la mano de la familia homoparental y lo que ella representa, surge un asunto de relevancia que ha ocupado la atención de muchos estudiosos del tema, se trata de la crianza dentro de familias homoparentales. Autores como González et al. (2002), Perrin et al. (2002) y Fernández y Arauxo (2004) han realizado aportes significativos al respecto, al presentar posiciones diversas a quienes ven con reserva o se oponen a la adopción por parte de padres del mismo sexo. Su posición con respecto al tema es que no existen diferencias significativas en cuanto a padres homosexuales o heterosexuales, tampoco consideran que los hijos de padres homosexuales se vean afectados en su desarrollo. (Castaño Suárez, Sánchez Trujillo, \& Viveros Chavarría, 2018, pág. 64)

La familia homoparental (aquella compuesta por dos hombres o dos mujeres, ya sea sin hijos o con hijos adoptivos, o hijos biológicos de alguno de los dos), una forma de familia que ha venido 
Año 16, Vol. 11, número 21, agosto-diciembre Sección: Dossier

DOXA

Pág.:212-225
María Isabel Arjón Galicia

DOI: $10.52191 /$ rdojs.2021.235

Perspectiva de la sociedad en la adopción.

apareciendo con mayor o menor fuerza en el debate público y que ejerce cierta presión para que se revise la legislación de los países donde no ha sido aprobada (Benítez Pérez, 2017, pág. 59)

\section{Antecedentes de la Adopción en México}

En México la adopción se estableció en el Código Civil de 1928 en su capítulo I Adopción el cual comprendía desde el artículo 390 al 410 . Mismos que establecían que la edad era tener más de cuarenta años para adoptar a un menor además de no tener descendencia. Este código presento una reforma en 1938, en el cual se reduce la edad para adoptar al contar con treinta años; posteriormente con la reforma de 1970, fue establecida la edad a los veinticinco años, y se eliminó el requisito donde mencionaba que era necesario no tener descendencia. La modificación más trascendental sobre la adopción, fue promulga en 1998, por medio de reformas y adiciones al Código Civil por parte del Distrito Federal en materia común y en toda la República en materia federal, esta permitió agregar la adopción plena cohabitando con la simple, donde además se estableció la nacional y la ejecutada por extranjeros. Y para la reforma de 1998 se reduce de 14 años a 12 años la edad para que exprese su consentimiento el adoptado para la adopción.

La autora María Elena Orta García en su artículo "la Adopción en México" nos señala que:

En el año 2000, el capítulo relativo a la adopción presenta de nuevo reformas y adiciones publicadas en la Gaceta del Distrito Federal del 25 de mayo de 2000 en la cual se derogan las disposiciones aplicables a la adopción simple. El 29 de mayo de 2000 se publica, en el Diario Oficial de la Federación, la Ley para la Protección de los Derechos de Niñas, Niños y Adolescentes, ley reglamentaria del artículo 4o. constitucional, que en sus artículos 25 y 26 establece disposiciones aplicables a la adopción, refiriéndose específicamente a la adopción internacional en su artículo 27. (Orta García, 2019, pág. 178)

De donde se toman las más nuevos reformas y aditamentos del Código Civil y de Procedimientos Civiles para el Distrito Federal en materia de adopción, los cuales se publicaron también en la Gaceta Oficial del Distrito Federal el 9 de junio de 2004. Aquí se retoma el concepto de que la adopción plena la cual se equipara al parentesco; en el Código de Procedimientos Civiles y nuevamente Orta García nos hace mención de que:

Se brinda la posibilidad de que los estudios socioeconómicos y psicológicos estén a cargo del Sistema Nacional para el Desarrollo Integral de la Familia, el que podrá acreditar a profesionales con experiencia en la materia y asimismo se faculta a la Secretaría de Salud, el Sistema para el Desarrollo Integral de la Familia del Distrito Federal, el Tribunal Superior de Justicia del Distrito Federal, la Procuraduría General de Justicia del Distrito Federal, para la práctica de estos estudios, cuando se trate de adopción nacional. (Orta García, 2019, pág. 178)

\section{La adopción en México}

Considerando el tema de adopción se cuenta con un concepto del autor Aguilar Torres en su artículo para dejarnos un poco más en claro a lo que se refiere la adopción donde menciona:

La adopción es definida como "Una institución que tiene como finalidad brindar protección y/o un medio familiar fundamentalmente a niños, niñas y adolescentes que se encuentran en estado 
de abandono o desamparo respecto de su familia originaria, creándose de este modo una situación similar a la filiación que se da entre padres e hijos consanguíneos con respecto a los adoptantes. (Aguilar Torres, 2020, pág. 52)

La adopción a lo largo de la historia ha tenido una serie de reformas y adiciones; inclusive en las diferentes entidades federativas se ha legislado de maneras muy diversas, esto debido a si la regulación del Derecho de Familia es local o estatal.

Anteriormente en cuestión de adopción se buscaba satisfacer solo los adoptantes pero posteriormente nos refiere Orta García que:

En los últimos años, contrario a la idiosincrasia imperante en el siglo pasado en el que se buscaba la satisfacción de los intereses de los adoptantes, la adopción ha sido reconocida como una medida de protección para los niños privados de un medio familiar; pero es ante todo, la posibilidad de brindar un hogar a un infante que por diferentes causas ha crecido con la carencia del amor y la protección que solo puede encontrar en el seno familiar. (Orta García, 2019, pág. 174)

Cuando un niño o menor de edad se encuentra en situación de abandono o falta de familia es cuando el estado interviene para dar cuidado y solución al menor brindando un entorno digno y acogedor donde este pueda desarrollarse sanamente, por esta razón es necesaria la figura de la adopción, cuya finalidad no es otra más que el menor encuentre una familia, que le brinde el cuidado y la seguridad de tener un desarrollo adecuado.

En la Ley de Adopción del Estado de Chihuahua en su artículo 4 en su fracción IV nos menciona un concepto de adopción el cual nos dice que:

IV. Adopción: Acto jurídico irrevocable en el cual se confiere la calidad legal de hija o hijo de la persona o personas adoptantes a la niña, niño o adolescente adoptado, y se generan los derechos y obligaciones inherentes a una relación de parentesco civil y filiación jurídica, que sustituye el biológico, extinguiendo todos sus efectos jurídicos, con la sola excepción que subsisten los impedimentos matrimoniales. (CNDH, Ley de Adopciones del Estado de Chihuahua, 2020, pág. 2)

La entidad federativa es quien se encarga de la figura de adopción, y por lo regular cada entidad cuenta con su regulación en materia de adopción; en algunos estados como en Chihuahua ya se contemplan leyes especializadas basadas en materia de adopción, donde se puede encontrar desde cómo realizar el trámite y el proceso para llevarse a cabo.

La adopción se encuentra regulada por instituciones que emanan del Estado, como el Sistema Nacional de Desarrollo Integral de la Familia, desde ahora denominado SNDIF. Dicha institución se apoya en la Ley General de los Derechos Niñas, Niños y Adolescentes, así como de su reglamento, los cuales reconocen y garantizan la protección de los derechos de menores y adolescentes a través del Estado, entre los cuales se encuentra el derecho a vivir en familia. Al mismo tiempo se otorgan las facultades a las autoridades que intervienen directamente en el proceso de adopción (Aguilar Torres, 2020, pág. 54) 
Pág.:212-225

\section{La adopción en el ámbito Internacional}

En la actualidad, en materia internacional se es reconocida la adopción como una forma de proteger a los niños que se encuentran privados de una familia. Relacionado con este tema se encuentra con la siguiente normativa:

A. Declaración de los Derechos del Niño (26 de noviembre de 1959). En esta declaración se contemplan diez principios, dentro de los cuales cabe destacar, en relación con la adopción, los principios 6 y 9; en el 6 refiere que enuncia que el niño, para el pleno y armonioso desarrollo de su personalidad, necesita amor y comprensión. Mientras que en el 9 hace énfasis a que el niño debe ser protegido contra toda forma de abandono, crueldad y explotación y no será objeto de ningún tipo de trata (Orta García, 2019, pág. 180)

B. Declaración sobre los Principios Sociales y Jurídicos Relativos a la Protección y al Bienestar de los Niños, con particular referencia a la adopción y la colocación en Hogares de guarda en los Planos Nacional e Internacional (adoptada por la Asamblea General de las Naciones Unidas el 3 de diciembre de 1986 en su resolución 41/85). La Asamblea General de la ONU reafirmando el principio 6 de la Declaración de los Derechos del Niño en 1959 y preocupada por el gran número de niños que quedan abandonados o huérfanos a causa de violencia, los disturbios internos, los conflictos armados, los desastres naturales, las crisis económicos o los problemas sociales, aprueban en 1986 esta declaración, que consta de veinticuatro artículos (Orta García, 2019, pág. 181)

C. Convención Interamericana sobre Conflictos de Leyes en Materia de Adopción de Menores (adoptada en la Paz, Bolivia, el 24 de mayo de 1984 - CIDIP — Los gobiernos de los Estados miembros de la Organización de los Estados Americanos (OEA) aprueban esta convención interamericana en 1984. México es Estado Parte desde el 12 de febrero de 1987 y entró en vigor en nuestro país el 26 de mayo de 1988. De acuerdo con su artículo 1 , la convención se aplicará a todos los menores bajo las formas de adopción plena, legitimación adoptiva y otras instituciones afines que, equiparen al adoptado a la condición de hijo, cuya filiación esté legalmente establecida, cuando el adoptante (adoptantes) tengan su domicilio en un Estado Parte y el adoptado su residencia habitual en otro Estado Parte (Orta García, 2019, pág. 182)

D. Convención Sobre los Derechos del Niño (adoptada por la Asamblea General de la ONU el 20 de noviembre de 1989 en su Resolución 44/25). Es el instrumento internacional de derechos humanos con el mayor número de ratificaciones, para nuestro país esta convención entró en vigor el 21 de octubre de 1990, y determina en sus artículos 20 y 21 los principios que deben regir las adopciones. En su artículo 21 especifica que los Estados Partes que reconocen o permiten el sistema de adopción cuidarán que el interés superior del niño sea la consideración primordial y asimismo velarán porque la adopción del niño sólo sea autorizada por las autoridades competentes, las que determinarán con arreglo a las leyes y a los procedimientos aplicables y sobre la base de toda la información perti- 
Año 16, Vol. 11, número 21, agosto-diciembre Sección: Dossier

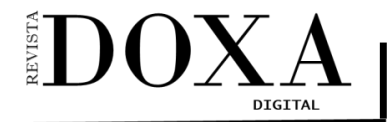
eISSN: 2594-2786
pISSN: 2395-8758
DOI: $10.52191 /$ rdojs.2021.235

Pág.:212-225
María Isabel Arjón Galicia

Perspectiva de la sociedad en la adopción..

nente y fidedigna, que la adopción es admisible en vista de la situación jurídica del niño en relación con sus padres, parientes y representantes legales y que, cuando así se requiera, las personas interesadas hayan dado con conocimiento de causa, su consentimiento a la adopción sobre la base del asesoramiento que pueda ser necesario (Orta García, 2019, pág. 182)

E. Protocolo Facultativo de la Convención Sobre los Derechos del Niño Relativo a la Venta de Niños, la Pornografía Infantil y la Utilización de Niños en la Pornografía (adoptado por la Asamblea General de las Naciones Unidas el 25 de mayo de 2000) Con la finalidad de asegurar el mejor logro de los propósitos de la Convención sobre los Derechos del Niño, los Estados Partes acordaron en su mayoría, adoptar este protocolo, que en su artículo 2 , inciso a, define a la venta de niños como todo acto o transacción en virtud del cual un niño es transferido por una persona o grupo de personas a otra a cambio de remuneración u otra retribución; en su artículo 3.5 insta a los Estados Partes a que adopten todas las disposiciones legales y administrativas pertinentes para que todas las personas que intervengan en la adopción de un niño actúen de conformidad con los instrumentos jurídicos aplicables (Orta García, 2019, pág. 183)

F. La Convención de la Haya sobre la Protección de Menores y la Cooperación en Materia de Adopción Internacional (1993) Dentro del marco jurídico internacional de la adopción, especial mención merece esta convención que ha sido ratificada por un número significativo de países miembros y no miembros de la Conferencia la Haya de derecho internacional privado. Este instrumento internacional fue suscrito por el Estado mexicano en 1993 y ratificado por el Senado de la República en 1994, inició su vigencia el 1o. de mayo de 1995. En esta forma, México se convirtió en el primer país en América Latina en ratificar esta convención y el tercero a nivel internacional en iniciar su aplicación, actualmente la convención ha sido ratificada por 50 países y se han adherido 28 , sumando 78 Estados Partes. Con la entrada en vigor de la convención se estima que el sistema de adopción nacional estadounidense se fortalece y las adopciones internacionales continuarán disminuyendo debido en gran medida a los elevados costos para la acreditación de las agencias, y éstos a su vez tendrán que elevar sus costos a los solicitantes de una adopción internacional (Orta García, 2019, pág. 183)

Todos y cada uno de los anteriores mencionados creados pensando y velando en el interés superior del menor, para un pleno desarrollo, y de esta manera formar personas con valores e ideales para que integren una sociedad de bien.

\section{El Interés Superior del menor en relación a la adopción}

Cabe mencionar que es importante dejar en claro a que se refiere con el concepto respecto al interés superior del niño donde el autor Garante nos refiere que: "se conecta con la idea de bienestar en la más amplia acepción del vocablo, y son sus necesidades las que definen su interés en cada momento de la historia y de la vida" (Garante, 2016, pág. 122) 
Año 16, Vol. 11, número 21, agosto-diciembre Sección: Dossier

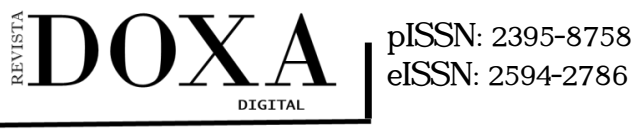

Pág.:212-225
María Isabel Arjón Galicia

DOI: $10.52191 /$ rdojs.2021.235

Perspectiva de la sociedad en la adopción.

Es por esto que se toma la adopción como una medida de protección del niño privado de una familia y se basa en su interés superior, no en lo que pueda desear el adulto que adoptara, primordialmente tiene su enfoque en dar al niño una familia y no un niño a una familia. En México aún nos enfrentamos a una falta de conocimiento respecto al tema de adopción y todo lo que esto conlleva, y es complicado aun tratándose de adopciones por heterosexuales, mas por homosexuales.

La autora Flores Osorio nos hace mención de lo que debemos entender por niño:

El artículo 1 de la Convención Americana de los Derechos del Niño entiende por niño todo ser humano menor de dieciocho años de edad. De conformidad con la primera parte del artículo 5 de la Ley General de los Derechos de las Niñas, Niños y Adolescentes, son niñas y niños los menores de 12 años, y adolescentes las personas de entre 12 años cumplidos y menos de 18 años de edad. (Flores Osorio, La Adopción por las Familias Homoparentales en México, 2017, pág. 396)

Dejando en claro que los menores de edad, son acreedores de derechos humanos tal como cualquier otra persona esto especificado en la Ley General de los Derechos de Niñas, Niños y Adolescentes donde nos dice que tienen derechos tales como el derecho a la vida, a la supervivencia y al desarrollo, derecho de prioridad, derecho a la identidad, derecho a vivir en familia, derecho a la igualdad sustantiva, derecho a no ser discriminado, derecho a vivir en condiciones de bienestar y a un sano desarrollo integral, entre otros que exigen que los menores estén situados en un entorno que les permita su alcance.

Nuevamente Flores Osorio refiere en su artículo que:

La Declaración Universal de los Derechos del Hombre y del Ciudadano, mostró los primeros pasos en el reconocimiento de los derechos del niño, como titular de ellos, por medio de quien ejerza la patria potestad. Más adelante, en la Convención de los Derechos del Niño de 1989, surge el reconocimiento de dos elementos altamente valorizados, dignidad humana y la autonomía; esto permite al niño considerarlo en la familia con el reconocimiento de sus derechos y la protección de sus intereses. (Flores Osorio, La Adopción por las Familias Homoparentales en México, 2017, pág. 397)

\section{Desarrollo Psicosocial}

Los niños, las niñas y los adolescentes forman parte del población más vulnerable de la sociedad, es por eso que es de suma importancia cuidar el desarrollo psicosocial de los menores de edad, es por eso que el existen diversas legislaciones tanto mexicanas como internacionales que buscan reconocer y establecer derechos así como su protección cuando el interés superior del menos se encuentre en riesgo.

Por eso es importante conocer un poco acerca del desarrollo psicosocial y con va desarrollándose a lo largo del crecimiento de cada una de las personas, y muy importante desde niños, nos enfocamos en la referencia que realiza según Erick Erikson donde nos argumenta que desde la niñez hasta la vejes pasamos por 8 conflictos, los primeras cuatro se ven centradas en la niñez y las otras 4 comprende desde la adolescencia hasta la vejez. El refiere que cuando enfrentamos el conflicto y es resuelto satisfactoriamente, tenemos un "crecimiento mental". Se desarrollara cada una de las etapas con la finalidad de comprender a lo que hace referencia el desarrollo psicosocial. 
Etapa I. Confianza vs Desconfianza. En esta etapa comprende entre los 0 y 18 meses de edad, en esta etapa él bebe crea confianza entre su entorno y sus padres, este vínculo va a depender de los padres; a este se le conoce como "vinculo del apego"

Etapa II. Autonomía vs vergüenza y duda. En esta etapa se comprende de los 18 meses a los 3 años de edad, cuando el niño comienza caminar y hablar, comienza a tener sentido de autonomía, por lo tanto Erik Erikson refiere que al superar con éxito esta fase los menores desarrollan una mayor autoestima, más sana y fuerte.

Etapa III. Iniciativa vs Culpa. En esta etapa se comprende de los 3 a los 5 años de edad, y es cuando crece el interés del niño por todo aquello que lo rodea y empieza a querer relacionarse con otros niños, explorando sus habilidades y capacidades

Etapa IV. Laboriosidad vs inferioridad. En esta etapa que es comprendida de los 5 a los 13 años de edad, ya siendo estos capaces de reconocer su capacidad y habilidades tienden a hacer comparaciones con los demás, desafiándose a cualquier actividad.

Etapa V. Exploración de la Identidad vs difusión de la identidad. Esta etapa comprende de los 13 a los 21 años de edad, empieza a elegir qué rol jugar dentro de la sociedad, pues comienza a formarse su propia personalidad.

Etapa VI. Intimidad vs Aislamiento. En esta etapa que va de los 21 a los 40 años de edad, El entorno y la vida social empiezan a dejar de ser tan importantes, se comienzan a trazar líneas intangibles sobre aspectos que la persona ya no está dispuesta a sacrificar por el agrado de los demás.

Etapa VII. Generatividad vs Estancamiento. En esta etapa se comprende de los 40 a los 60 años, aquí la persona inicia a dedicar más tiempo a su familia. Se interesa en ser beneficioso para poder ofrecer buen futuro a sus seres queridos, se busca ser y sentirse útil de esta forma.

Etapa VIII. Integridad del yo vs desesperación. En esta etapa se comprende de los 60 años en adelante, aquí es cuando la persona comienza a ver los cambios físicos y retrocede al pasado y ve si lo que hizo fue productivo, y volver a ello puede generar nostalgia o una sensación de que lo que se realizó valió la pena debido a su logro.

\section{Conclusión}

En conclusión, la adopción es un tema complejo el cual debe ser revisado de manera minuciosa, se encuentra de por medio el interés superior del menor que es lo primordial por lo que hay que velar al momento de iniciar cualquier proceso de adopción; ya que el menor es el principal actor dentro de este procedimiento. Lo importante es brindar la protección para este grupo vulnerable, y que más niños que se encuentran en un estado de orfandad puedan tener acceso a una familia que les brinde lo necesario para un buen desarrollo físico y mental, así de esta manera ofrecer un mejor futuro para ellos y que de esta forma desempeñen un buen papel dentro de la sociedad.

De la misma forma otorgar la protección y reconocer los derechos a aquellos matrimonios ho- 
mosexuales; que les son reconocidos a los matrimonios heterosexuales, dejando de lado la discriminación, permitiendo a estos también que puedan formar familia, uno de los principales derechos humanos que tiene toda persona.

Además es de suma importancia que tanto autoridades, como legisladores y todas aquellas personas que se encuentran desempeñando actividades donde se colabore para que se respeten tratados, convenios y demás leyes que protegen los derechos de menores y comunidad LGBTIQ+, así como a la sociedad en general sobre todo aquellos quienes buscan adoptar, se encuentren informados respecto a temas tan sensibles como lo son la adopción de los menores, así como acerca de la comunidad LGBTIQ+

Se espera que los resultados contribuyan a realizar una propuesta para dar un seguimiento a la adopción de los menores de edad realizadas por familias homoparentales, para de esta manera tener un sustento acerca del desarrollo psicosocial de los menores y así brindar los mismos derechos de todas las familias de tener acceso a la adopción, para que así mas niños puedan tener la oportunidad de crecer dentro de una familia que les permita tener un mejor desarrollo.

\section{Referencias}

Aguilar Torres, E. I. (2020). La adopción en méxico: estudio descriptivo del proceso adoptivo. Perfiles de las Ciencias Sociales, 50-75.

Ángulo Menasse, A. (2017). Profesionales de la Salu Mental y su Relación con las Familias Homoparentales en México. ScienceDirect, 17-33.

Arenas Valdés , R. H., \& Reyes Martínez , J. D. (2019). El Derecho a la Adopción por Parejas Homosexuales. Universidad Autónoma del Estado de México, 1-37.

Benítez Pérez, M. E. (2017). La familia: Desde lo tradicional a lo discutible. CEDEM / NOVEDADES EN POBLACIÓN, 58-68.

Castaño Suárez, M., Sánchez Trujillo, M. P., \& Viveros Chavarría, E. F. (2018). Familia Homoparental, Dinámicas Familiares y Prácticas Parentales. Revista Latinoamericana de Estudios de Familia, 51-70.

CNDH. (2020). Ley de Adopciones del Estado de Chihuahua. Chihuahua: Subdirección de Informática Jurídica, Dirección General de Tecnologías de Información y Comunicaciones, Comisión Nacional de los Derechos Humanos.

CNDH. (11 de 01 de 2021). Ley General de los Derechos de niñas, niños y adolescentes. Obtenido de https://www.cndh.org.mx/sites/default/files/documentos/2021-01/Ley_GDNNA.pdf

Flores Osorio, I. C. (2017). La Adopción por las Familias Homoparentales en México. Ecos sociales, 372-410. 
Sección: Dossier

DOI: $10.52191 /$ rdojs.2021.235

Pág.:212-225
María Isabel Arjón Galicia

Perspectiva de la sociedad en la adopción. eISSN: 2594-2786

Flores Osorio, I. C. (2017). La Adopción por las Familias Homoparentales en México. Ecos sociales, 1-37.

Garante, R. M. (2016). El interés superior del niño en la filiación por adopción. Anales de la Facultad de Ciencias Jurídicas y Sociales, 116-126.

H. Congreso del Estado, S. d. (2014). Código de Procedimientos Familiares del Estado de Chihuahua. Chihuahua: $\mathrm{H}$. Congreso del Estado, Secretaría de Asuntos Legislativos y Jurídicos y Biblioteca Legislativa "Carlos Montemayor Aceves".

Juarez Méndez , A. J., \& Chávez Intriago, M. Y. (2016). La Experiencia de Ser Familia en una Pareja Homosexual. Dailnet, 69-89.

Laguna Maqueda, Ó. E. (2016). Crítica a los conceptos homoparentalidad y familia homoparental: alcances y límites desde el enfoque de las relaciones y vínculos parentales de las personas de diversidad sexual. La ventana. Revista de estudios de género.

Marrero, E. (s.f.). Página del Prof. Eddie Marrero. Obtenido de Principios de Psicología II (Psic 3002): http://academic.uprm.edu/ eddiem/psic3002/id43.htm

Martínez Vasallo, H. M. (2015). La familia: una visión interdisciplinaria. Revista Médica Electrónica, 523-534.

Martínez Zuluaga, J. P., Sáenz Lozada , M. L., \& Echeverry Raad, J. (2019). Efectos de adopción y crianza homoparental. Revistas Umanizales.

Moliner Navarro, R. (2012). Adopción, Familia y Derecho. luris Tantum Revista Boliviana de Derecho.

Muñoz Machado, S. (15 de 12 de 2017). Real Academia Española. Obtenido de Real Academia Española: https://dpej.rae.es/

Orta García, M. E. (2019). La adopción en México. Revista de Derecho Privado, 173-188.

Pérez Contreras, M. M. (2010). La adopción. En M. d. Contreras, Derecho de Familia y Sucesiones (págs. 1-257). México, D.F.: Nostra Ediciones.

Pérez González, A. A. (2016). Homoparentalidad, Un Nuevo Tipo de Familia. Universidad de Chile, 1-261.

Placeres Hernández , J. F., Olver Moncayo, D. H., Rosero Mora, G. M., Urgilés Calero, R. J., \& Abdala-Jalil Barbadillo, S. (2017). La Familia Homoparental en la Realidad y la Diversidad Familiar Actual. Revista Médica Electrónica.

Placeres Hernández, J. F., Olver Moncayo, D. H., Rosero Mora, G. M., Urgilés Calero, R. J., \& Abdala-Jalil Barbadillo, S. (2017). La familia homoparental en la realidad y la diversidad familiar actual. Revista Medica Electronica.

Regader, B. (s.f.). Psicologia y Mente. Obtenido de La Teoría del Desarrollo Psicosocial de Erik 
Año 16, Vol. 11, número 21, agosto-diciembre

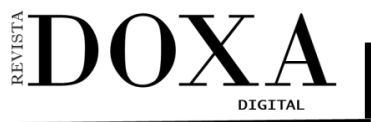

Sección: Dossier

DOI: 10.52191/rdojs.2021.235

Pág.:212-225
María Isabel Arjón Galicia

Perspectiva de la sociedad en la adopción.

Erikson: https://psicologiaymente.com/desarrollo/teoria-del-desarrollo-psicosocial-erikson Reyes Martínez, J. D. (2019). El derecho a la adopción por parejas homosexuales. Revista Indizada, 1-29.

Rodríguez, E. M. (16 de 06 de 2020). La mente es Maravillosa. Obtenido de Las etapas del desarrollo psicosocial de Erikson: https://lamenteesmaravillosa.com/las-etapas-del-desarrollopsicosocial-de-erikson/

Salinas Hernández, H. M. (2017). Matrimonio igualitario en México. El Cotidiano, 95-104.

Torres, J. M. (s.f.). Reflexiones Críticas de Derecho Comparado Sobre Cambios Legislativos en Materia de Adopción por Parejas Homosexuales en Holanda y sus Antiguas Colonias. Revista Crítica de Historia de las Relaciones Laborales y de la Política Social.

UNICEF. (12 de 04 de 2020). Convención sobre los Derechos del Niño. Obtenido de Convención sobre los Derechos del Niño: https://www.un.org/es/events/childrenday/pdf/derechos.pdf

Vidal Basilio , M. (s.f.). Derecho a tener una familia: adopción homoparental, entre prejuicios y realidades. 1-22.

Zúñiga Ortega, A. V. (2012). ¿Qué hacer en México con la familia homoparental? Revista Legislativa de Estudios Sociales y de Opinión Pública, 239-254. 